\title{
PENGARUH METODE FERMENTASI DAN PENAMBAHAN URINE KELINCI TERHADAP KUALITAS PUPUK ORGANIK CAIR
}

\section{THE EFFECT OF FERMENTATION METHOD AND ADDITION OF RABBIT URINE ON THE QUALITY OF LIQUID ORGANIC FERTILIZER}

\author{
David Richard Hendarto ${ }^{1 凶}$ dan Dina Rotua Valentina Banjarnahor ${ }^{1}$ \\ ${ }^{1}$ Jurusan Agroteknologi, Fakultas Pertanian dan Bisnis, Universitas Kristen Satya Wacana \\ $\bowtie$ Komunikasi Penulis, email: drh8898@gmail.com \\ DOI:http://dx.doi.org/10.23960/jtep-lv10i2.139-146
}

Naskah ini diterima pada 2 Maret 2021; revisi pada 11 April 2021;

disetujui untuk dipublikasikan pada 12 April 2021

\begin{abstract}
The Minang Bangkit Merbabu Farmer Group use organic materials and produce their own liquid organic fertilizer. This liquid organic fertilizer is made of varied ingredients: rabbit urine, cow's milk, free-range chicken eggs, palm sugar, coconut water, pineapple, shrimp paste, bamboo roots, ginger, and turmeric. Composting is strongly affected by $\mathrm{pH}$ and aeration method. Liquid organic fertilizer made by farmers usually have an initial $\mathrm{pH}$ of around 3.7. This mixture was usually composted using semi-anaerobic method. Through this study, we wanted to find out whether different methods of aeration and addition of rabbit urine would result in different liquid organic fertilizer quality. The quality of liquid organic fertilizer includes $C$-organic, total nitrogen, total phosphorus and total potassium. The experiment was designed as a factorial randomized block design. There were 2 factors tested: rabbit urine volume and aeration method. There were two levels of rabbit urine volume : original and modified ones. There were three levels of aeration method: aerobic, semi-anaerobic, and anaerobic. In total, there were six treatments and four replication for each treatment. The results of the analysis showed that composting with the aerobic method at the original rabbit urine volume could increase the concentration of nutrient content so that it gave the highest yield. It is different from composting at a modified rabbit urine volume, because the highest yield is in the anaerobic method.
\end{abstract}

Keywords: aerated, organic, rabbit urine volume

\begin{abstract}
ABSTRAK
Kelompok Tani Minang Bangkit Merbabu menggunakan bahan organik dan menghasilkan pupuk organik cair (POC). POC dibuat dari bahan yang bervariasi: urine kelinci, susu sapi, telur ayam kampung, gula aren, air kelapa, nanas, terasi, umbi bambu, jahe, dan kunyit Pengomposan sangat dipengaruhi oleh metode aerasi dan level pH. POC yang dibuat petani biasanya memiliki pH awal campuran sekitar 3,7 dan biasanya dikomposkan dengan metode semi-anaerob. Melalui studi ini, kami ingin mengetahui apakah perbedaan metode aerasi dan penambahan urine kelinci akan menghasilkan kualitas POC yang berbeda. Kualitas POC meliputi C-organik, nitrogen total, fosfor total dan kalium total. Percobaan dirancang sebagai rancangan acak kelompok faktorial. Ada 2 faktor yang diuji yaitu metode aerasi dan volume urine kelinci. Ada 2 tingkat volume urine kelinci: asli dan yang dimodifikasi. Ada 3 tingkatan metode aerasi: aerob, semi-anaerob, dan anaerob. Total ada 6 perlakuan dan 4 ulangan untuk setiap perlakuan. Hasil analisis menunjukkan bahwa pengomposan metode aerob pada volume urine kelinci yang asli dapat meningkatkan konsentrasi kandungan hara sehingga memberikan hasil yang paling tinggi. Berbeda dengan pengomposan pada volume urine kelinci yang dimodifikasi, karena hasil yang paling tinggi justru terdapat pada metode anaerob.
\end{abstract}

Kata kunci: aerasi, organik, volume urine kelinci 


\section{PENDAHULUAN}

Pada dasarnya, tanaman dalam pertumbuhan dan perkembangannya memerlukan dua jenis unsur hara, yaitu unsur hara makro dan mikro. Dari keseluruhan unsur makro dan mikro yang harus tersedia bagi tanaman, hanya unsur N, P, dan K yang dibutuhkan tanaman dalam jumlah yang lebih besar dibandingkan unsur-unsur lainnya. Ketiga unsur tersebut sering disebut unsur hara makro utama (Rina, 2015). Salah satu jenis bahan yang dapat memenuhi kebutuhan unsur hara $\mathrm{N}$, $\mathrm{P}$, dan $\mathrm{K}$ dan ramah lingkungan adalah pupuk organik cair (POC), yang diperoleh dari proses pengomposan bahan organik di dalam wadah komposter (Hadisuwito, 2007).

Penggunaan pupuk organik dipercaya membawa manfaat lebih bagi produk-produk pertanian. Produk menjadi lebih sehat, lebih ramah lingkungan dan dapat mengurangi dampak negatif dari bahan kimia yang berbahaya bagi manusia dan lingkungan. Oleh karena itu, dalam kebijakan pengembangan industri pupuk di Indonesia disertakan pula program pengembangan pupuk organik. Pemerintah memberikan fasilitas untuk mendorong pengembangan pupuk organik oleh swasta maupun melalui kemitraan swasta dan BUMN dengan memanfaatkan fasilitas distribusi BUMN (Susetya, 2018).

Kelompok Tani Minang Bangkit Merbabu yang berlokasi di Dusun Seloduwur, Desa Batur, Kecamatan Getasan merupakan salah satu kelompok tani di Indonesia yang menerapkan sistem pertanian organik. Segala proses budidaya tanaman menggunakan bahan-bahan organik sebagai bahan dasarnya, salah satunya POC. POC yang digunakan merupakan hasil produksi sendiri dengan memanfaatkan limbahlimbah seperti urine kelinci, susu segar sapi, telur ayam kampung, gula aren, air kelapa, nanas, terasi udang, akar bambu, jahe, dan kunyit. Limbah-limbah tersebut digunakan oleh petani karena mudah didapatkan. Beberapa bahan tersebut memiliki kandungan unsur hara cukup tinggi sehingga memang berpotensi sebagai penyedia hara bagi tanaman.

Terdapat beberapa faktor yang penting diperhatikan selama proses pengomposan seperti aerasi dan volume urine kelinci. Aerasi merupakan metode dalam pengaturan oksigen yang dibutuhkan oleh mikroorganisme selama pengomposan. Penguraian bahan organik dapat terjadi pada kondisi dengan aerob (oksigen) dan anaerob (tanpa oksigen). Mikroorganisme pengurai yang terlibat dalam kedua metode tersebut membutuhkan ketersediaan oksigen yang berbeda. Beberapa bakteri yang dominan di kondisi aerob adalah Escherichia coli, Streptococcus sp. dan Staphylococcus sp.. Bakteri yang terdapat di kondisi anaerob antara lain adalah Escherichia coli, Streptococcus sp., Staphylococcus sp., dan Clostridium sp. (Hermanus et al., 2015).

Urine kelinci dikenal sebagai sumber pupuk organik yang potensial dalam budidaya tanaman. Pemanfaatan limbah ini diduga berpengaruh signifikan dalam suatu integrasi usaha sayuran ternak berbasis kelinci di sentra-sentra produksi hortikultura dan banyak dimanfaatkan pada tanaman hortikultura (Sajimin et al., 2010). Urine kelinci yang berjumlah sedikit tersebut mengandung unsur hara $\mathrm{N}, \mathrm{P}$ dan $\mathrm{K}$ yang lebih baik dibandingkan dengan kotoran ternak lainnya yaitu $2,72 \% \mathrm{~N}, 1,1 \% \mathrm{P}$ dan $0,5 \% \mathrm{~K}$ (Rosniawaty et al., 2005). Peningkatkan pertumbuhan dan produksi tanaman melalui pemberian unsur hara NPK yang tinggi yang terkandung dalam urin kelinci.

Pada pengomposan, $\mathrm{pH}$ dipengaruhi oleh bahan organiknya sendiri dan aktivitas bakteri. Umumnya, pH pada awal proses pengomposan rendah karena aktivitas mikroorganisme pengurai menghasilkan asam. Akan tetapi, lambat laun $\mathrm{pH}$ akan menuju netral. $\mathrm{pH}$ yang optimum untuk proses pengomposan berkisar antara 5,5 sampai 8 (Sutanto, 2002). Bakteri

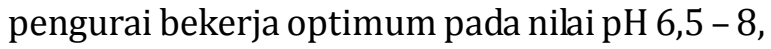
sementara jamur pengurai bekerja efektif pada kisaran pH 5 - 5,8 (Cooperband, 2000).

Ketersediaan oksigen dan volume urine kelinci akan mempengaruhi kehidupan dan aktivitas mikroorganisme (aerob/anaerob) yang terlibat dalam pengomposan dan aktivitas penguraiannya. Jika mikroorganisme (aerob/ anaerob) tersebut tidak mampu beraktivitas karena kelebihan/kekurangan oksigen dan level $\mathrm{pH}$ yang tidak sesuai akibat dari penambahan 
urine kelinci. Proses dekomposisi dan mineralisasi akan terhambat dan bahkan terhenti. Akibatnya, bahan-bahan organik tersebut tidak diubah secara sempurna menjadi unsur hara sehingga unsur hara yang dihasilkan lebih sedikit Maka dari itu, pengaturan aerasi dan volume urine kelinci akan berpengaruh pada kualitas hasil pengomposan (kandungan Corganik, N, P, K, dsb) (Juanda et al., 2011). Oleh karena belum diketahuinya pengaruh pengaturan aerasi dan volume urine kelinci terhadap pengomposan cair yang dilakukan petani, maka peneliti ingin mengetahui pengaruh beberapa metode aerasi dan volume urine kelinci selama pengomposan terhadap kualitas POC Kelompok Tani Minang Bangkit Merbabu.

\section{BAHAN DAN METODE}

Penelitian ini dilakukan di jalan Wahid Hasyim No.1 pada bulan September - November 2020. Alat-alat yang digunakan dalam penelitian ini adalah termometer, $\mathrm{pH}$ meter, toples plastik dan penutupnya, serta alat tulis. Bahan-bahan yang diperlukan dalam penelitian ini adalah air, seperti urine kelinci, susu segar sapi, telur ayam kampung, gula aren, air kelapa, nanas, terasi udang, akar bambu, jahe, dan kunyit.

Percobaan disusun dalam rancangan acak kelompok faktorial (RAKF) dengan 2 faktor dan 4 ulangan. Faktor I adalah 2 volume urine kelinci yaitu volume asli dan volume modifikasi. Faktor II adalah 3 jenis aerasi yaitu aerob, semi anaerob dan anaerob.

\subsection{Pembuatan POC}

Pada pembuatan POC dengan volume urine kelinci asli, disiapkan terlebih dahulu semua bahan seperti urine kelinci ( $125 \mathrm{ml}$ ), susu sapi segar (250 ml), terasi udang (15 gram), telur ayam kampung (11/4 butir), gula aren $(125$ gram), nanas (450 gram), akar bambu (1 gram), air kelapa (1250 ml), jahe (125 gram), kunyit (125 gram), air ( $250 \mathrm{ml}$ ). Takaran bahan-bahan yang disebutkan sebelumnya berdasarkan dari racikan Kelompok Tani Minang Bangkit Merbabu. Semua bahan tersebut kemudian diblender dan dituangkan kedalam wadah toples plastik, sesuai masing-masing perlakuan jenis aerasi. Pada pembuatan POC volume urine kelinci modifikasi, perbedaan bahan hanya terdapat pada volume urine kelinci karena adanya penambahan yaitu menjadi $6125 \mathrm{ml}$. Penambahan tersebut dilakukan agar menciptakan kondisi pH netral (7) yang sebelumnya memiliki pH yang asam $(3,7)$.

Perlakuan dengan jenis aerasi aerob, toples nantinya akan dibuka penutupnya selama pengomposan dilakukan. Pada jenis aerasi semi anaerob, toples ditutup dengan penutupnya yang sudah diberi lubang kecil dengan diameter $5 \mathrm{~cm}$. Sedangkan pada jenis aerasi anaerob, maka toples akan ditutup rapat dengan penutupnya. Setiap 2 hari sekali kompos cair akan diaduk dengan arah melawan arah jarum jam (kiri). Pada perlakuan dengan aerasi anaerob, toples akan dibuka penutupnya selama 30 detik agar dapat dilakukan pengadukan.

\subsection{Analisis Kandungan Hara dan Data}

Pada hari ke 0, 15, dan 30 dilakukan analisis kandungan $\mathrm{C}$-organik, $\mathrm{N}$ total, $\mathrm{P}$ total, dan $\mathrm{K}$ total yang dilakukan di Balai Pengkajian Teknologi Pertanian (BPTP) Jawa Tengah. C-organik dianalisis dengan metode spektrofotometri, $\mathrm{N}$ total dianalisis dengan metode Kjeldahl, $\mathrm{P}$ total dianalisis dengan metode spektrofotometri, $\mathrm{K}$ total dianalisis dengan metode spektrofotometri. Data yang diperoleh dianalisis menggunakan analisis sidik ragam (program SAS dan Microsoft Excell 2013) dan apabila ada pengaruh maka dilanjutkan dengan menggunakan uji beda nyata jujur (BNJ) 5\%.

\section{HASIL DAN PEMBAHASAN}

\subsection{Kandungan C-organik}

Kandungan C-organik selama pengomposan pada setiap perlakuan memiliki nilai yang bervariasi seperti pada Tabel 1. Pada perlakuan volume urine kelinci asli memiliki kandungan C-organik yang lebih tinggi dibandingkan pada perlakuan volume urine kelinci modifikasi. Hal ini menunjukkan bahwa penambahan pelarut berupa urine kelinci dapat menurunkan konsentrasi C-organik pada POC.

POC dengan perlakuan volume urine kelinci asli yang memiliki $\mathrm{pH}$ awal 3,7 pada semua jenis aerasi mengalami penurunan konsentrasi C- 
organik pada hari ke-15. Pelakuan volume urine kelinci asli dengan metode anaerob merupakan perlakuan dengan kandungan C-organik paling tinggi jika dibandingkan dengan kedua metode aerasi lainnya pada volume urine kelinci asli, yaitu $2,26 \%$. Hal ini bisa saja disebabkan karena POC pada perlakuan anaerob tidak mengalami penguapan karena wadah ditutup sehingga konsentrasi C-organik dapat bertahan didalam wadah. Bahkan hingga hari ke-30, perlakuan volume urine kelinci asli dengan metode anaerob masih memiliki kandungan C-organik paling tinggi, yaitu $2,58 \%$. Selain metode anaerob, perlakuan POC dengan perlakuan volume urine kelinci asli pada metode aerob juga mengalami peningkatan pada hari ke-30, terkecuali dengan perlakuan volume urine kelinci asli pada metode semi anaerob yang tetap mengalami penurunan.

POC dengan perlakuan volume urine kelinci modifikasi yang memiliki $\mathrm{pH}$ awal 7 pada semua metode aerasi mengalami penurunan pada hari ke-15 hingga hari ke-30. Kandungan C-organik yang dihasilkan juga tidak terlalu berbeda antar metode aerasi. Hal ini bisa terjadi karena POC diberi tambahan pelarut berupa urine kelinci sehingga konsentrasi bahan organik pada kompos cair berkurang. Kandungan yang paling tinggi pada hari ke-15 terdapat pada perlakuan volume urine kelinci modifikasi dengan metode semi anaerob dan anaerob, yaitu $1 \%$. Pada hari ke-30, perlakuan volume urine kelinci modifikasi dengan metode anaerob memiliki kandungan $\mathrm{C}$-organik yang paling tinggi jika dibandingkan dengan kedua metode aerasi lainnya, yaitu 0,91\%. Perbedaan kandungan Corganik pada hari ke-15 dengan hari ke-30 tidak jauh berbeda pada semua perlakuan volume urine kelinci dan semua metode aerasi sehingga pengomposan cukup dilakukan 15 hari saja agar menghemat waktu.

\subsection{Nitrogen Total}

Kandungan N total pada POC menghasilkan data yang bervariasi, dapat dilihat pada Tabel 2 . Kandungan awal $\mathrm{N}$ total pada perlakuan volume urine kelinci modifikasi lebih tinggi dibandingkan pada volume urine kelinci asli. Hal ini dikarenakan adanya penambahan pelarut berupa urine kelinci pada perlakuan terebut. Urine kelinci merupakan salah satu bahan organik yang mengandung unsur hara $\mathrm{N}$ yang cukup tinggi yaitu 2,11 \% (Rosniawaty et al., 2005).

POC volume urine kelinci asli yang memiliki $\mathrm{pH}$ awal 3,7 lalu dikomposkan dengan metode aerob dan anaerob mengalami peningkatan konsentrasi $\mathrm{N}$ total pada hari ke-15. Metode aerob menghasilkan konsentrasi $\mathrm{N}$ yang paling tinggi yaitu $0,12 \%$. Hal ini bisa saja terjadi karena adanya penguapan pelarut berupa air dalam wadah. Metode aerob bersifat terbuka sehingga ketika adanya bahan organik, oksigen dan nutrisi untuk mikroorganisme, maka saat pengomposan dilakukan akan menghasilkan karbondioksida, amonia, dan ion sulfat yang dapat lepas dalam bentuk gas tetapi pada saat bersamaan gas $\mathrm{N}$ dan air juga mudah menguap. Air menguap dalam jumlah yang lebih banyak daripada $\mathrm{N}$ sehingga mengakibatkan konsentrasi $\mathrm{N}$ pada kompos cair meningkat. Bahkan hingga hari ke-30, POC volume urine kelinci asli dengan kedua metode aerasi tersebut masih mengalami peningkatan konsentrasi $\mathrm{N}$ total dengan metode aerob yang masih paling tinggi yaitu $0,17 \%$.

Tabel 1. Kandungan C-organik

\begin{tabular}{lccc}
\hline \multirow{2}{*}{ Perlakuan } & \multicolumn{3}{c}{ Hari Pengamatan } \\
\cline { 2 - 4 } & $\mathbf{0}$ & $\mathbf{1 5}$ & $\mathbf{3 0}$ \\
\hline Volume asli, aerob & $3.68 \mathrm{a}$ & $1.77 \mathrm{ab}$ & $2.35 \mathrm{a}$ \\
Volume asli, semi anaerob & $3.68 \mathrm{a}$ & $1.66 \mathrm{~b}$ & $1.61 \mathrm{ab}$ \\
Volume asli, anaerob & $3.68 \mathrm{a}$ & $2.26 \mathrm{a}$ & $2.58 \mathrm{a}$ \\
Volume modifikasi, aerob & $1.13 \mathrm{~b}$ & $0.92 \mathrm{c}$ & $0.79 \mathrm{~b}$ \\
Volume modifikasi, semi anaerob & $1.13 \mathrm{~b}$ & $1.00 \mathrm{c}$ & $0.73 \mathrm{~b}$ \\
Volume modifikasi, anaerob & $1.13 \mathrm{~b}$ & $1.00 \mathrm{c}$ & $0.91 \mathrm{~b}$ \\
\hline
\end{tabular}

Keterangan: Angka-angka yang diikuti huruf yang sama dalam kolom yang sama tidak berbeda nyata pada BNJ taraf $5 \%$ 
POC dengan perlakuan volume urine kelinci modifikasi yang memiliki $\mathrm{pH}$ awal 7 lalu dikomposkan dengan ketiga metode aerasi mengalami penurunan konsentrasi $\mathrm{N}$ total pada hari ke-15. Hasil analisis dari ketiga metode aerasi tidak jauh berbeda, yaitu 0,15\% (aerob dan anaerob) dan 0,14\% (semi anaerob). Perbedaan metode aerasi pada pengomposan dengan volume urine kelinci modifikasi tidak terlalu berpengaruh terhadap kandungan $\mathrm{N}$ total yang dihasilkan. Selain penguapan air, $\mathrm{pH}$ sangat berpengaruh terhadap kesetimbangan ammonia di air. Penguapan air akan menyebabkan naiknya konsentrasi $\mathrm{N} /$ lebih pekat. Naiknya $\mathrm{pH}$ akan memudahkan konversi ammonia ke gas sehingga mudah lepas dari larutan. Dengan demikian pada pH 7, konsentrasi N cenderung konstan. Pada hari ke-30, pengomposan dengan perlakuan volume urine kelinci modifikasi dengan metode semi anaerob dan anaerob mengalami peningkatan konsentrasi $\mathrm{N}$ total dimana yang paling tinggi terdapat pada metode anaerob, yaitu $0,16 \%$. Kandungan tersebut sama seperti kandungan awalnya.

Berdasarkan data pada Tabel 2, dapat dilihat bahwa pengomposan cukup dilakukan selama 15 hari karena sudah menghasilkan $\mathrm{N}$ total yang cukup tinggi jika dibandingkan dengan pengomposan selama 30 hari. Selain waktu yang lebih singkat, kandungan $\mathrm{N}$ total yang dihasilkan juga tidak berbeda jauh dengan dengan pengomposan selama 30 hari.

\subsection{Rasio $\mathrm{C} / \mathrm{N}$}

$\mathrm{C} / \mathrm{N}$ Rasio yang diperoleh pada POC yang telah dibuat masih tergolong dapat terdekomposisi karena menurut Ruskandi (2006), bahan organik bersifat mudah terdekomposisi jika memiliki nisbah C/N antara 20-35. Semakin tinggi $\mathrm{C} / \mathrm{N}$ rasio, semakin sulit bahan organik akan terurai. Sementara jika $\mathrm{C} / \mathrm{N}$ rasio terlalu rendah, meski awalnya terjadi dekomposisi yang sangat cepat tetapi selanjutnya kecepatannya akan menurun karena kekurangan $\mathrm{C}$ sebagai sumber energi. $\mathrm{C} / \mathrm{N}$ rasio yang terlalu rendah akan menghasilkan $\mathrm{NH}_{3}$ sehingga aktivitas mikroorganisme akan terhambat (Mulyani, 2014).

$\mathrm{C} / \mathrm{N}$ rasio pada saat awal pembuatan $\mathrm{POC}$ menunjukkan bahwa POC dengan perlakuan volume urine kelinci modifikasi lebih mudah untuk terdekomposisi. Pengomposan hingga 30 hari juga menunjukkan bahwa $\mathrm{C} / \mathrm{N}$ rasio pada POC dengan perlakuan volume urine kelinci modifikasi memiliki nilai yang lebih kecil daripada POC dengan perlakuan volume urine kelinci asli. Perbedaan jenis aerasi tampaknya tidak memberikan pengaruh yang nyata terhadap nilai $\mathrm{C} / \mathrm{N}$ rasio pada tiap perlakuan, namun perbedaan volume urine kelinci yang memberikan pengaruh yang cukup nyata. Berdasarkan Tabel 3, C/N rasio pada saat hari ke-15 memiki nilai yang tidak terlalu berbeda dengan hari ke-30 sehingga kompos cair sudah siap digunakan saat 15 hari pengomposan agar waktu lebih efisien dengan kualitas $\mathrm{C} / \mathrm{N}$ rasio yang dihasilkan cukup baik.

\subsection{Posfor Total}

Kandungan $\mathrm{P}$ total pada kompos cair yang dihasilkan menunjukkan perbedaan yang cukup nyata dimana pada perlakuan volume urine kelinci modifikasi atau perlakuan dengan pemberian pelarut berupa urine kelinci yang lebih banyak dapat menurunkan konsentrasi $\mathrm{P}$ total pada kompos cair. Namun, perbedaan

Tabel 2. Kandungan N Total

\begin{tabular}{lccc}
\hline \multirow{2}{*}{ Perlakuan } & \multicolumn{3}{c}{ Hari Pengamatan } \\
\cline { 2 - 4 } & $\mathbf{0}$ & $\mathbf{1 5}$ & $\mathbf{3 0}$ \\
\hline Volume asli, aerob & $0.09 \mathrm{~b}$ & $0.12 \mathrm{~b}$ & $0.17 \mathrm{a}$ \\
Volume asli, semi anaerob & $0.09 \mathrm{~b}$ & $0.09 \mathrm{c}$ & $0.13 \mathrm{~b}$ \\
Volume asli, anaerob & $0.09 \mathrm{~b}$ & $0.11 \mathrm{~b}$ & $0.15 \mathrm{ab}$ \\
Volume modifikasi, aerob & $0.16 \mathrm{a}$ & $0.15 \mathrm{a}$ & $0.13 \mathrm{~b}$ \\
Volume modifikasi, semi anaerob & $0.16 \mathrm{a}$ & $0.14 \mathrm{a}$ & $0.15 \mathrm{ab}$ \\
Volume modifikasi, anaerob & $0.16 \mathrm{a}$ & $0.15 \mathrm{a}$ & $0.16 \mathrm{a}$ \\
\hline
\end{tabular}

Keterangan: Angka-angka yang diikuti huruf yang sama dalam kolom yang sama tidak berbeda nyata pada BNJ taraf $5 \%$ 
Tabel 3. Kandungan C/N Rasio

\begin{tabular}{lccc}
\hline \multirow{2}{*}{ Perlakuan } & \multicolumn{3}{c}{ Hasil Pengamatan } \\
\cline { 2 - 4 } & $\mathbf{0}$ & $\mathbf{1 5}$ & $\mathbf{3 0}$ \\
\hline Volume asli, aerob & $39.66 \mathrm{a}$ & $14.48 \mathrm{~b}$ & $13.47 \mathrm{a}$ \\
Volume asli, semi anaerob & $39.66 \mathrm{a}$ & $17.35 \mathrm{ab}$ & $12.05 \mathrm{ab}$ \\
Volume asli, anaerob & $39.66 \mathrm{a}$ & $20.20 \mathrm{a}$ & $16.70 \mathrm{a}$ \\
Volume modifikasi, aerob & $7.27 \mathrm{~b}$ & $5.84 \mathrm{c}$ & $6.16 \mathrm{bc}$ \\
Volume modifikasi, semi anaerob & $7.27 \mathrm{~b}$ & $6.75 \mathrm{c}$ & $4.94 \mathrm{c}$ \\
Volume modifikasi, anaerob & $7.27 \mathrm{~b}$ & $6.59 \mathrm{c}$ & $5.52 \mathrm{c}$ \\
\hline
\end{tabular}

Keterangan: Angka-angka yang diikuti huruf yang sama dalam kolom yang sama tidak berbeda nyata pada BNJ taraf $5 \%$

Tabel 4. Kandungan P Total

\begin{tabular}{lccc}
\hline \multirow{2}{*}{ Perlakuan } & \multicolumn{3}{c}{ Hari Pengamatan } \\
\cline { 2 - 4 } & $\mathbf{0}$ & $\mathbf{1 5}$ & $\mathbf{3 0}$ \\
\hline Volume asli, aerob & $0.03 \mathrm{a}$ & $0.03 \mathrm{a}$ & $0.08 \mathrm{a}$ \\
Volume asli, semi anaerob & $0.03 \mathrm{a}$ & $0.03 \mathrm{ab}$ & $0.04 \mathrm{ab}$ \\
Volume asli, anaerob & $0.03 \mathrm{a}$ & $0.03 \mathrm{ab}$ & $0.04 \mathrm{ab}$ \\
Volume modifikasi, aerob & $0.01 \mathrm{~b}$ & $0.02 \mathrm{bc}$ & $0.01 \mathrm{~b}$ \\
Volume modifikasi, semi anaerob & $0.01 \mathrm{~b}$ & $0.02 \mathrm{c}$ & $0.01 \mathrm{~b}$ \\
Volume modifikasi, anaerob & $0.01 \mathrm{~b}$ & $0.02 \mathrm{bc}$ & $0.02 \mathrm{~b}$ \\
\hline
\end{tabular}

Keterangan: Angka-angka yang diikuti huruf yang sama dalam kolom yang sama tidak berbeda nyata pada BNJ taraf $5 \%$

tersebut tidaklah tampak pada perlakuan antar metode aerasi yang dapat dilihat seperti pada Tabel 4. Menurut Rosniawaty et al. (2005), kandungan $\mathrm{P}$ total pada urine kelinci sebesar $1,1 \%$.

POC dengan perlakuan volume urine kelinci asli yang memiliki $\mathrm{pH}$ awal 3,7 pada semua metode aerasi terjadi penurunan konsentrasi $P$ total pada hari ke-15. Kandungan P total yang dihasilkan juga sama pada perlakuan volume urine kelinci asli semua metode aerasi, yaitu $0,03 \%$. Pada hari ke-30, perlakuan volume urine kelinci asli dengan semua metode aerasi terjadi peningkatan dan pada metode aerob memiliki kandungan $\mathrm{P}$ total yang paling tinggi, yaitu $0,08 \%$. Kompos cair dengan perlakuan volume urine kelinci modifikasi yang memiliki $\mathrm{pH}$ awal 7 pada semua metode aerasi terjadi peningkatan dan memiliki kandungan $P$ total yang sama, yaitu $0,02 \%$. Pada hari ke-30, perlakuan volume urine kelinci modifikasi dengan metode aerob dan semi anaerob mengalami penurunan sedangkan perlakuan dengan metode anaerob tidak berubah seperti pada hari ke-15 yaitu 0,02 \%.
Adanya peningkatan kandungan $\mathrm{P}$ total yang cukup tinggi pada POC perlakuan volume urine kelinci asli dengan metode aerob dimana sebesar 0,08\% sedangkan kedua metode aerasi lainnya hanya sebesar $0,04 \%$ dapat saja disebabkan oleh adanya bangkai belatung pada sampel POC yang diambil. Sehingga, kandungan $P$ total pada POC diduga menjadi tidak seimbang atau terjadi perubahan angka pada hasil analisis akibat adanya bangkai belatung tersebut. Jika dilihat kandungan $\mathrm{P}$ total pada Tabel 4, maka dapat disimpulkan bahwa pengomposan tidak perlu memakan waktu yang cukup lama (30 hari), karena hasil kandungan hara yang tertera tidak menunjukkan perbedaan yang signifikan dengan pengomposan selama 15 hari dan ini berlaku pada semua jenis perlakuan.

\subsection{Kalium Total}

Kandungan $\mathrm{K}$ total pada POC yang dihasilkan dapat dilihat pada Tabel 5, dimana kandungan $\mathrm{K}$ total pada perlakuan volume urine kelinci modifikasi lebih tinggi dibandingan dengan perlakuan volume urine kelinci asli. Penambahan pelarut berupa urine kelinci dapat membantu meningkatkan konsentrasi $\mathrm{K}$ total pada kompos cair tersebut karena diantara 
Tabel 5. Kandungan K Total

\begin{tabular}{lccc}
\hline \multirow{2}{*}{ Perlakuan } & \multicolumn{3}{c}{ Hari Pengamatan } \\
\cline { 2 - 4 } & $\mathbf{0}$ & $\mathbf{1 5}$ & $\mathbf{3 0}$ \\
\hline Volume asli, aerob & $0.27 \mathrm{~b}$ & $0.32 \mathrm{~b}$ & $0.33 \mathrm{~b}$ \\
Volume asli, semi anaerob & $0.27 \mathrm{~b}$ & $0.24 \mathrm{~b}$ & $0.29 \mathrm{~b}$ \\
Volume asli, anaerob & $0.27 \mathrm{~b}$ & $0.26 \mathrm{~b}$ & $0.23 \mathrm{~b}$ \\
Volume modifikasi, aerob & $0.77 \mathrm{a}$ & $0.67 \mathrm{a}$ & $0.61 \mathrm{a}$ \\
Volume modifikasi, semi anaerob & $0.77 \mathrm{a}$ & $0.67 \mathrm{a}$ & $0.52 \mathrm{a}$ \\
Volume modifikasi, anaerob & $0.77 \mathrm{a}$ & $0.62 \mathrm{a}$ & $0.53 \mathrm{a}$ \\
\hline
\end{tabular}

Keterangan: Angka-angka yang diikuti huruf yang sama dalam kolom yang sama tidak berbeda nyata pada BNJ taraf $5 \%$

semua bahan organik dalam pembuatan kompos cair, kandungan hara $\mathrm{K}$ total tertinggi terdapat pada urine kelinci. Menurut Rosniawaty et al. (2005), kandungan K pada urine kelinci sebesar $0,5 \%$.

POC dengan perlakuan volume urine kelinci asli yang memiliki pH awal 3,7 pada metode aerob mengalami peningkatan pada hari ke-15, yaitu $0,32 \%$ dan kedua metode aerasi lainnya mengalami penurunan. Hal ini bisa saja terjadi karena adanya penguapan pelarut berupa air yang menyebabkan konsentrasi $\mathrm{K}$ dalam kompos cair meningkat. Pada hari ke-30, hanya perlakuan volume urine kelinci asli dengan metode anaerob yang mengalami penurunan sedangkan kedua metode aerasi lainnya mengalami peningkatan. Kandungan $\mathrm{K}$ total yang paling tinggi terdapat pada metode aerob, yaitu $0,33 \%$.

POC dengan perlakuan volume urine kelinci modifikasi yang memiliki $\mathrm{pH}$ awal 7 pada semua metode aerasi mengalami penurunan pada hari ke-15. Perlakuan pada metode aerob dan semi anaerob memiliki kandungan yang sama dan merupakan yang paling tinggi, yaitu 0,67 \% . Pada hari ke-30, semua perlakuan volume urine kelinci modifikasi metode aerasi kembali mengalami penurunan. Kandungan $\mathrm{K}$ total yang paling tinggi terdapat pada metode aerob, yaitu $0,61 \%$. Kandungan $\mathrm{K}$ total yang terus mengalami penurunan bisa saja disebabkan oleh adanya penambahan pelarut berupa urine kelinci pada awal pengomposan sehingga konsentrasi $\mathrm{K}$ total menjadi turun seiring berjalannya waktu. Mikroorganisme pada POC diduga tidak dapat bekerja secara maksimal pada perlakuan volume urine kelinci modifikasi sehingga menyebabkan penurunan kandungan K. Perbedaan metode aerasi pada kedua perlakuan volume urine kelinci tidak menunjukkan perbedaan yang cukup signifikan. Kandungan $\mathrm{K}$ total yang dihasilkan pada hari ke-15 dengan hari ke-30 tidak memiliki perbedaan yang begitu besar sehingga pengomposan cukup dilakukan 15 hari saja agar lebih menghemat waktu.

Berdasarkan standar Pupuk Organik Cair (POC) dari Menteri Pertanian (2019), dimana Corganik minimal $10 \%$ dan kandungan hara makro $(\mathrm{N}+\mathrm{P}+\mathrm{K})$ minimal $2 \%$, maka dapat disimpulkan bahwa semua perlakuan belum memenuhi standar untuk parameter C-organik dan kandungan hara makro. Adapun metode aerasi pada perlakuan volume urine kelinci asli yang menghasilkan kandungan yang paling tinggi untuk masing-masing parameter adalah Corganik pada metode anaerob, $\mathrm{N}$ total, $\mathrm{P}$ total dan $\mathrm{K}$ total pada metode aerob. Pada perlakuan dengan volume urine kelinci modifikasi, metode aerasi yang menghasilkan kandungan masingmasing parameter yang paling tinggi adalah Corganik, $\mathrm{N}$ total dan $\mathrm{P}$ total pada metode anaerob, $\mathrm{K}$ total pada metode aerob.

Diduga bahwa pada POC dengan perlakuan volume urine kelinci asli, mikroorganisme yang bekerja lebih dominan adalah mikroorganisme aerob, terlihat pada kandungan hara hasil dari analisis yang paling tinggi didominasi pada metode aerob dalam menghasilkan $\mathrm{N}$ total, $\mathrm{P}$ total dan K total. Berbeda pada POC dengan perlakuan volume urine kelinci modifikasi, mikroorganisme anaerob justru bekerja lebih dominan karena menghasilkan kandungan Corganik, $\mathrm{N}$ total dan $\mathrm{P}$ total yang lebih tinggi. Melihat pembuatan POC yang dibuat oleh Kelompok Tani Minang Bangkit Merbabu dengan metode semi anaerob pada perlakuan dengan 
perlakuan volume urine kelinci asli, maka dapat dikatakan bahwa pelakuan tersebut masih belum tepat dalam menghasilkan kompos cair dengan kualitas kandungan hara yang tinggi. Kami lebih menyarankan dalam pembuatan POC dengan perlakuan volume urine kelinci asli untuk menggunakan metode aerob karena melihat hasil kandungan yang lebih tinggi pada $\mathrm{N}$ total, $\mathrm{P}$ total dan $\mathrm{K}$ total yang diperlukan oleh kelompok tani dalam melakukan kegiatan budidaya tanaman.

\section{KESIMPULAN}

Berdasarkan hasil penelitian dan pembahasan diatas, dapat kami simpulkan bahwa POC pada perlakuan volume urine kelinci asli pada metode aerob menghasilkan $\mathrm{N}$ total, $\mathrm{P}$ total dan $\mathrm{K}$ total yang paling tinggi dan metode anaerob menghasilkan C-organik yang paling tinggi. Berbeda dengan POC pada perlakuan volume urine kelinci modifikasi dimana metode anaerob menghasilkan C-organik, $\mathrm{N}$ total dan $\mathrm{P}$ total yang paling tinggi dan metode aerob menghasilkan $\mathrm{K}$ total yang paling tinggi.

\section{DAFTAR PUSTAKA}

Cooperband, L.R. 2000. Composting : Art and Science of Organic Waste Conversion to a Valuable Soil Resource. Laboratory Medicine, 31(6):203-209.

Hadisuwito, S. 2007. Membuat Pupuk Kompos Cair. Jakarta : Redaksi AgroMedia Pustaka.

Hermanus, M.B., Polii, B., dan Mandey, L.C. 2015. Pengaruh Perlakuan Aerob dan Anaerob Terhadap Variabel BOD, COD, pH dan Bakteri Dominan Limbah Industri Desiccated Coconut PT. Global Coconut Radey, Minahasa Selatan. Jurnal Ilmu dan Teknologi Pangan, 3(2) : 48-59.
Juanda, I. dan Nurdiana. 2011. Pengaruh Metode dan Lama Fermentasi Terhadap Mutu Mikroorganisme Lokal. Jurnal Floratek, 6:140-143.

Menteri Pertanian. 2019. Keputusan Menteri Pertanian Indonesia. No.261/KPTS/ SR.310.M.4.2019 tentang Persyaratan Teknis Minimal Pupuk Organik, Pupuk Hayati, dan Pembenah Tanah.

Mulyani, H. 2014. Optimasi Perancangan Model Pengomposan. Jakarta : Trans Info Media.

Rina, D. 2015. Manfaat Unsur N, P, dan K bagi Tanaman. BPTP Kaltim (Balai Pengkajian Teknologi Pertanian Kalimantan Timur).

Rosniawaty, S., Sudirja, R., dan Afrianto, H. 2015. Pemanfaatan Urin Kelinci dan Urin Sapi Sebagai Alternatif Pupuk Organik Cair pada Pembibitan Kakao (Theobroma cacao L.). Jurnal Kultivasi, 14(1): 32-36.

Ruskandi. 2006. Pembuatan Kompos Limbah Kebun Pertanaman Kelapa Polikultur. Buletin Teknik Pertanian, 11(1):33-36.

Sajimin, Y., Rahardjo, C., dan Purwantari, N. D. 2010. Potensi Kotoran Kelinci sebagai Pupuk Organik dan Pemanfaatannya pada Tanaman Pakan dan Sayuran. Lokakarya Nasional Potensi dan Peluang Pengembangan Usaha Agribisnis Kelinci. Hal: 156 - 161.

Susetya, D. 2018. Panduan Lengkap Membuat Pupuk Organik Untuk Tanaman Pertanian dan Perkebunan. Yogyakarta : Pustaka Baru Press.

Sutanto, R. 2002. Penerapan Pertanian Organik. Yogyakarta: Kanisius. 